\title{
Prevalence of diabetic retinopathy
} Age, sex, and duration of diabetes

\author{
HAROLD A. KAHN AND ROBERT F. BRADLEY \\ From the National Eye Institute, Bethesda, Maryland, and the Joslin Clinic, Boston, Massachusetts
}

This paper is a by-product of planning for a casecontrol study intended to evaluate various possible risk factors in diabetic retinopathy by comparing diabetics of 15 or more years' duration who do not have retinopathy, with diabetics of 15 or more years' duration who do. An analysis of Joslin Clinic patients for the period January to June 1972 by age, sex, duration of diabetes, and presence of retinopathy was made to find out whether the Clinic had sufficient cases of long-term diabetes without retinopathy to provide the desired number for the case-control study. The answer was 'yes' and detailed planning for the case-control study will proceed. In the course of obtaining our answer other interesting results were obtained and are now reported.

\section{Material and methods}

A computer list was prepared identifying by number every patient who had attended the Joslin Clinic during the period January to June 1972. The list included both inpatients and outpatients. Altogether there were II 580 different individuals arranged in order of patient number. Each page listed 60 patients. Since it would be convenient to review clusters of patient folders filed in close proximity to each other, we decided to pick our sample in consecutive sets of five. The patients listed on each page could be categorized in $5^{6}$ such sets as follows: first to fifth, second to sixth ... fifty-sixth to sixtieth. From each page we chose one of these $5^{6}$ clusters at random for our sample. This sampling ratio of $5: 60$ yielded a sample of 965 cases, which were then classified according to age, sex, diabetes status, duration of diabetes, and presence of retinopathy by a Joslin Clinic assistant working according to the following rules and definitions:

Age was calculated as at the last visit.

Diabetes was to be recorded as present if glucose tolerance tests (Somogyi-Nelson test on whole blood) showed two or more instances of the following values: I I $\mathrm{mg}$ per cent or more fasting, $\mathrm{I} 6 \mathrm{o} \mathrm{mg}$ per cent or more at one hour, or $120 \mathrm{mg}$ per cent or more at two hours. For older cases where the test was done using the Folin-Wu method, equivalent values were 130,180 , and 140 , respectively. If the file folder suggested that the case was nondiabetic, the clinic assistant was instructed to review it with one of us (RFB) before so recording it. The Joslin Clinic records onset of diabetes as the date of definite diagnosis, unless it is possible to identify an earlier date on the basis of definite diabetic symptoms. For example, if diabetes had been definitely diagnosed according to the glucose tolerance test rules, as referred to above, in June 1960 , and the patient reported that he had had extreme thirst for one year preceding that period, the date of onset would be entered in the Joslin records as June 1959. The duration of diabetes was calculated as the interval from onset to date of last visit.

Retinopathy was determined in the following manner: If one or more of the following elements of retinopathy were reported on two or more examinations by a diabetes specialist, or on a single examination by an ophthalmologist, retinopathy was considered present-haemorrhages, hard or waxy exudates, microaneurysms, red dots, new vessels, retinitis proliferans, intraretinal microvascular abnormalities, vitreous haemorrhage, preretinal haemorrhage, or fibrous tissue on or in front of disc. The following categories were excluded from the diagnosis of retinopathy: soft or cotton wool exudates, sclerosis, Keith-Wagener changes, venous irregularities, venous tortuosity, dark veins, sludging, and arterial venous compression. The clinic assistant was advised that, if any record was not clear with respect to any of the above elements, she was to consult with RFB. The 965 cases were reviewed by the clinic assistant according to the above rules, and the status of the patient regarding age, sex, presence of diabetes, duration of diabetes, and presence of retinopathy was recorded. Duration was recorded in three classes: under Io years, Io to 14 years, and 15 years and over.

After this, we selected a sample of 125 of the 965 patients for independent verification of the clinic assistant's work by a diabetes specialist who also followed the rules specified above. A list of these cases was returned to the Joslin Clinic identifying patients by number only, and a specialist in diabetes reviewed the file folders for these patient numbers and reported his findings as to age, sex, diabetes status, duration of diabetes, and presence of retinopathy.

The ophthalmic examination at the Joslin Clinic is made through an undilated pupil by a house physician specializing in diabetes. However, if he sees some sign of progression, is doubtful as to what he sees, is suspicious as to retinal involvement, or has obtained a history of visual complaints, the pupil is then dilated, or the patient is referred to an ophthalmologist for an examination. It is likely that the proportion of cases found to have retinopathy by these methods is less than if all patients had been examined by an ophthalmologist through a dilated pupil. On the other hand, it is reasonable to suppose that the 
prevalence of retinopathy we find may be greater than that to be found in a general population because of a tendency for the more serious cases of diabetes to be overrepresented in a clinic. In addition, because long duration of diabetes is understood to be a risk factor for retinopathy, the increased suspicion associated with increased duration would tend towards a higher proportion of pupillary dilations and/or referrals to an ophthalmologist for the longer duration cases. This bias towards more thorough examination for the longer duration cases would exaggerate any duration effect actually present. Unfortunately, with respect to all three possible biases, we can do little more than note the direction of their effect. Apart from our opinion that the degree of bias is too small to have a serious effect on our results, we are unable to quantify them to any useful degree of precision.

\section{Results}

Among the 125 cases used to verify the original results, 27 discrepancies were reported. Each of these was checked again to minimize the chance of a mistake, and 3 of them were eliminated by this process. Of the 24 discrepancies remaining, 2 were reported age differences of more than two years and I was a reported difference in sex. These discrepancies indicated that we were dealing with different patients because of a patient number error (names not on lists) and thus our verification comparison was limited to 122 cases among which we found a total of 2 I discrepancies related to duration of diabetes or presence of retinopathy. The details of the comparison between the clinic assistant's classification and the verification by the diabetologist are shown in Tables I and II.

Table I Verification of duration of diabetes

\begin{tabular}{|c|c|c|c|}
\hline $\begin{array}{l}\text { Original } \\
\text { duration } \\
\text { category } \\
\text { (years) }\end{array}$ & $\begin{array}{l}\text { Number } \\
\text { reviewed }\end{array}$ & $\begin{array}{l}\text { Number } \\
\text { verified }\end{array}$ & $\begin{array}{l}\text { Number } \\
\text { changed }\end{array}$ \\
\hline$<$ Io & 26 & 25 & $\mathrm{I} \rightarrow$ Io years \\
\hline $10-14$ & $3^{2}$ & 27 & $\begin{array}{l}2 \rightarrow I 5 \text { years } \\
3 \rightarrow 19+\text { years }\end{array}$ \\
\hline \multirow[t]{2}{*}{$15+$} & 64 & 60 & $4 \rightarrow<$ I 5 years \\
\hline & 122 & 112 & 10 \\
\hline
\end{tabular}

For I 12 patients out of the 122 the category for the duration of diabetes was confirmed to be as originally reported as shown in Table I. In one case, the change from classification of 'under 10' to 'exactly ro' may not have been an error as the verification took place almost a year after the original report. Similarly, two cases classified in duration category 10 to 14 years and changed to I5-year duration may also not have been an error. Definite error changes consisted of 3 out of the 32 patients in the io to 14 year duration category that were changed to 19 years or more, and 4 in the 15 and over duration category that were changed to under 15 years. In none of these instances was the number of definite errors Io per cent or more, and it seemed reasonable not to change the original data regarding the classification of duration.

Table II shows the results of the verification of retinopathy. Only two categories showed errors. In the group of 27 patients originally reported in the Io to I4 years' duration category as without retinopathy, 3 were reported by the verifier to have retinopathy as of September 1972 or before, a date earlier than the clinic assistant's review. In the group of 31 patients originally reported as without retinopathy in the duration category 15 years or more, 8 were changed to 'with retinopathy' by the verifier. Again, all were reported to have retinopathy before September 1972. These changes affected over Io per cent of the patients in the particular categories and were applied through an adjustment to the data from all the 965 patients. The adjustment was made in the following way: the category of duration Io to I4 years was adjusted to increase the number of cases with retinopathy originally reported, by adding to the retinopathy group and subtracting from the nonretinopathy group I I per cent (rounded to the nearest whole number) of those in this category who were originally reported as not having retinopathy. Similarly, in the duration category 15 years or more, the adjustment represented 26 per cent of those cases originally reported as not having retinopathy. The adjusted results obtained (Table III) show the strong effect of duration overall and in each age group, and indicate that the duration effect may be stronger for women than for men. Age shows a significant positive association with retinopathy prevalence $(\mathbf{P}<0.05)$ in patients with less than 10 years' diabetes. Patients with duration categories 10 to I 5 years, or I 5 or more years, do not show increasing prevalence of retinopathy with age.

\section{Table II Verification of retinopathy status}

\begin{tabular}{|c|c|c|c|}
\hline $\begin{array}{l}\text { Original } \\
\text { status }\end{array}$ & $\begin{array}{l}\text { Number } \\
\text { reviewed }\end{array}$ & $\begin{array}{l}\text { Number } \\
\text { verified }\end{array}$ & $\begin{array}{l}\text { Number } \\
\text { changed }\end{array}$ \\
\hline Yes & $4^{2}$ & 42 & o \\
\hline \multicolumn{4}{|l|}{ No } \\
\hline (Dur. < Io) & 22 & 22 & 0 \\
\hline (Dur. IO-I 4 ) & 27 & 24 & \multirow{2}{*}{$\begin{array}{l}3 \rightarrow Y_{\text {es* }}^{*} \\
8 \rightarrow Y_{\text {es** }}\end{array}$} \\
\hline$($ Dur. I $5+)$ & $3 I$ & 23 & \\
\hline
\end{tabular}

* I I per cent adjustment (3/27)

** 26 per cent adjustment $(8 / 31)$

In an effort to quantify more accurately the separate effects of age and duration on the percentage of retinopathy than is possible by inspection of Table III, 
Table III Adjusted percentage* of patients with diabetic retinopathy by sex, age, and duration of diabetes

\begin{tabular}{|c|c|c|c|c|c|c|c|c|c|c|c|c|}
\hline \multirow[b]{4}{*}{$\begin{array}{l}\text { Sex } \\
\text { Age (yrs) }\end{array}$} & & & & \multicolumn{9}{|c|}{ Duration category } \\
\hline & \multicolumn{3}{|c|}{ Total patients } & \multicolumn{3}{|l|}{$<$ Io } & \multicolumn{3}{|l|}{$10-14$} & \multicolumn{3}{|l|}{ I5t } \\
\hline & \multirow[t]{2}{*}{ Total } & \multicolumn{2}{|c|}{ With retinopathy } & \multirow[t]{2}{*}{ Total } & \multicolumn{2}{|c|}{ With retinopathy } & \multirow[t]{2}{*}{ Total } & \multicolumn{2}{|c|}{ With retinopathy } & \multirow[t]{2}{*}{ Total } & \multicolumn{2}{|c|}{ With retinopathy } \\
\hline & & No. & Per cent & & No. & Per cent & & No. & Per cent & & No. & Per cent \\
\hline \multirow{2}{*}{$\begin{array}{l}\text { Both } \\
\text { Total }\end{array}$} & & & & & & & & & & & & \\
\hline & $914^{* *}$ & 232 & 25 & $5^{13}$ & 34 & 7 & $14^{8}$ & 39 & 26 & 253 & I 59 & 63 \\
\hline$<35$ & 234 & 33 & 14 & 167 & 4 & 2 & 33 & 7 & $2 I$ & 34 & 22 & 65 \\
\hline $35-44$ & 86 & 26 & 30 & 39 & I & 3 & 12 & 3 & - & 35 & 22 & 63 \\
\hline $45-54$ & 146 & 35 & 24 & 89 & 6 & 7 & 27 & 8 & - & 30 & $2 \mathrm{I}$ & 70 \\
\hline $55-64$ & 202 & 57 & 28 & 105 & 6 & 6 & 32 & 8 & 25 & $6_{5}$ & 43 & 66 \\
\hline $65-74$ & I 79 & 56 & $3 I$ & 85 & I0 & 12 & $3 \mathrm{I}$ & 8 & 26 & 63 & 38 & 60 \\
\hline $75+$ & 67 & 25 & 37 & 28 & 7 & - & 13 & 5 & - & 26 & I3 & - \\
\hline \multicolumn{13}{|l|}{ Men } \\
\hline Total & $4^{69}$ & 114 & 24 & 256 & 22 & 9 & 83 & 17 & 20 & I 30 & 75 & $5^{8}$ \\
\hline$<35$ & 120 & I6 & 13 & 84 & 4 & 5 & I 7 & 2 & - & 19 & Io & - \\
\hline $35-54$ & I 26 & 27 & $2 I$ & 83 & 6 & 7 & 18 & 6 & - & 25 & 15 & - \\
\hline $55-74$ & 189 & $6 \mathrm{r}$ & 32 & 80 & I I & 14 & 39 & 8 & 20 & 70 & $4^{2}$ & $6 o$ \\
\hline $75+$ & 34 & Io & 29 & 9 & $\mathbf{I}$ & - & 9 & $\mathbf{I}$ & - & 16 & 8 & - \\
\hline \multicolumn{13}{|l|}{ Women } \\
\hline Total & 445 & I I 9 & 27 & 257 & 12 & 5 & $6_{5}$ & 23 & 35 & I 23 & 84 & 68 \\
\hline$<35$ & II 4 & I 7 & 15 & 83 & o & $o$ & I 6 & 5 & - & I 5 & 12 & - \\
\hline $35-54$ & 106 & 35 & 33 & 45 & I & 2 & 21 & 6 & - & 40 & 28 & 70 \\
\hline $55-74$ & 192 & 52 & 27 & IIO & 5 & 5 & 24 & 8 & - & 58 & 39 & 67 \\
\hline $75+$ & 33 & I5 & 45 & 19 & 6 & - & 4 & 4 & - & 10 & 5 & - \\
\hline
\end{tabular}

* See text for discussion of adjustment. Percentage not shown if less than 30 cases in denominator ** Of the 965 cases reviewed, only 914 were found to be definitely diabetic

we have fitted a multiple logistic model to the unadjusted original data for individuals. Our method of verification and adjustment permits correction of grouped data in the manner described above, but we cannot know which of the individual original reports, not included in the sample selected for verification, should be changed. Since the adjustment, in effect, increased the proportion of those with retinopathy only among those who had had diabetes for ro years or more, our model will necessarily understate the degree of association between duration and retinopathy. Another defect of the model used is that it ignores the interaction between age and duration that we have already noted, but since the age effect is weak this may not be serious. A detailed mathematical derivation (Cornfield, Gordon, and Smith, I96I) and an elementary exposition of the logic underlying the multiple logistic model (Kahn, Herman, Medalie, Neufeld, Riss, and Goldbourt, 197I) are available elsewhere. The model ignoring interaction leads to an equation of the following form:

Proportion with retinopathy $=$ $\mathrm{I} / \mathrm{I}+\exp -\left(\alpha+\beta_{1}\right.$ age $+\beta_{2}$ duration $)$

The coefficients $\alpha, \beta_{1}$, and $\beta_{2}$, computed by the method of least squares, are as follows:

\begin{tabular}{|c|c|c|}
\hline Coefficient & $M e n$ & Women \\
\hline $\begin{array}{l}\alpha \\
\beta_{1}\end{array}$ & $\begin{array}{r}-3.765 \\
0.0115\end{array}$ & $\begin{array}{r}-4^{\cdot 625} \\
0 \cdot 014^{1}\end{array}$ \\
\hline$\beta_{2}$ & $\mathrm{o}^{\cdot} \mathrm{I} 354$ & 0.2120 \\
\hline
\end{tabular}

The age coefficients $\left(\beta_{1}\right)$ are clearly very much smaller than the duration coefficients $\left(\beta_{2}\right)$ pointing to the far lesser importance of another year of age compared with another year of disease. Two applications of the multiple logistic formula may be instructive. 
For 20-year-old women with 5-years' duration:

Estimated prevalence $=$

$$
\begin{gathered}
\mathrm{I} / \mathrm{I}+\exp -(-4 \cdot 625+(0.014 \mathrm{I}) 20+(0 \cdot 2120) 5) \\
=0.04
\end{gathered}
$$

For 65-year-old men with 20-years' duration:

Estimated prevalence $=$

$$
\begin{gathered}
\mathrm{I} / \mathrm{I}+\exp -(-3.765+(0.0115) 65+(0.1354) 20) \\
=0.42^{2}
\end{gathered}
$$

These estimates compare well with the unadjusted data originally reported. Thus, among 83 women under 35 years of age with a duration < ro years, there were no cases of retinopathy or zero per cent prevalence, and among 70 men 55 to 74 years of age with diabetes for over 15 years there were 32 cases of retinopathy, or an uncorrected prevalence of 46 per cent. The model is useful in that it adjusts each of the variables of interest for the effect of the other and provides a

\begin{tabular}{|c|c|c|c|c|}
\hline \multirow[b]{2}{*}{ Group } & \multirow[b]{2}{*}{$\begin{array}{l}\text { Age } \\
\text { (yrs) }\end{array}$} & \multirow[b]{2}{*}{$\begin{array}{l}\text { Duration } \\
\text { (vrs) }\end{array}$} & \multicolumn{2}{|c|}{$\begin{array}{l}\text { Estimated prevalence } \\
\text { of retinopathy }\end{array}$} \\
\hline & & & Men & Women \\
\hline A & 60 & 10 & 0.15 & $0 \cdot 16$ \\
\hline B & $6 o$ & 15 & $0 \cdot 26$ & 0.35 \\
\hline G & 65 & Io & $0 \cdot 16$ & 0.17 \\
\hline
\end{tabular}
quantitative estimate of each variable's importance. This latter point can be illustrated by comparing the estimated prevalence rate for three groups as follows:

Group B differs from Group A only in having the disease 5 years longer. Group C differs from Group A only in being 5 years older. The 5 years of increase in age is associated with a trivial increase in prevalence, but the 5 additional years of duration are associated with almost a doubling of the prevalence for men and more than a doubling of the prevalence rate for women. Our impression from Table III that duration was more strongly associated with prevalence of retinopathy for women than for men seems to be confirmed by the model.

\section{Discussion}

We have three findings:

I. Retinopathy prevalence is strongly and positively associated with duration of diabetes.

2. Retinopathy prevalence is positively related to age only for diabetics with a duration of the disease of under io years.

3. The prevalence of retinopathy may be more strongly related to duration in women than in men.

In reviewing other published reports we note so many unstandardized (and often unspecified) conditions relating to patient selection and diagnostic practice that we do not believe it particularly useful to compare the prevalence findings directly. The prevalence level is, of course, a function of these unstandardized conditions of measurement, and we believe it more valuable to consider the associations found, within individual studies, between retinopathy prevalence and other variables.

The strong positive association with duration is frequently reported (Goldberg, 1972) and needs no further comment. Our finding that retinopathy prevalence is positively associated with age only for those who have had diabetes for less than Io years seems not to have been clearly stated previously although the data in many published reports reflect this interaction between age and duration. Jackson, Goldin, and Marine (1966) came close to stating that the effect of age is shown only among cases of short duration but, nevertheless, they reported in their summary '... frequency of retinopathy rose with duration of diabetes and with age'. The following data on percentage of prevalence of retinopathy in patients at a clinic are abstracted from Burditt, Caird, and Draper (1968). Although we have been discussing current age rather than age at diagnosis, the correspondence is necessarily very high for fixed periods

\begin{tabular}{|c|c|c|c|}
\hline \multirow[b]{2}{*}{ Age at diagnosis } & \multicolumn{3}{|c|}{ Duration of diabetes } \\
\hline & $0-9$ & $10-14$ & I5t \\
\hline$<30$ & Io & 45 & 73 \\
\hline $30-59$ & 30 & 53 & 68 \\
\hline $60+$ & 37 & 44 & （59） \\
\hline
\end{tabular}
of duration, as in these data.

Prevalence of retinopathy (percentage) (after Burditt and others, 1968)

All percentages are based on 100 cases or more except for those aged 60 or over who have had diabetes for 15 years or more, which is based on 27 cases

In commenting on the more detailed table from which these data were abstracted, the authors stated that '.. the pattern of frequency of retinopathy in relation to duration of diabetes is largely determined by age at diagnosis of diabetes,' and 'The younger the patient at diagnosis of diabetes, the longer the duration of diabetes before retinopathy becomes common, but a frequency of about 80 per cent is reached after 20 to 25 years of diabetes in all age groups'. In a later publication, Goldberg (1972) stated 'Presumably, therefore, ageing makes the retinal vasculature more vulnerable to the diabetic process whatever it may be, and makes the older patient more likely than his younger counterpart to develop retinopathy within a given period of time'.

Our interpretation of the evidence is that the 
positive association of ageing with retinopathy is limited to the first ro years of the disease. However, because our data on duration include the broad category of 'under io years', the ageing effect we observe may include a component arising from correlation between age and duration within this ro-year interval. In any event, if youthful vasculature is protective, then ro years of diabetic disease seems to wear it out. If older vasculature is more vulnerable, then ro years of disease is sufficient to convert more youthful retinal vasculature to equal vulnerability.

Our observation that women have a stronger relationship between prevalence and duration than men may be attributable to chance and is generally not borne out in other data. We simply note it and omit all speculation about its meaning since we lack confidence that it represents a general truth.

\section{Summary}

From a list of all patients seen at the Joslin Clinic in a recent 6 -month period, a random sample of 965 was selected for record review by a clinic assistant. A house physician specializing in diabetes then verified and adjusted the assistant's work as necessary. The data were analysed both by simple cross-classification and by fitting a multiple logistic risk function. As often reported previously, we found a strong positive association between retinopathy and duration of diabetes. One of our findings which has not been so clearly reported in earlier papers is that the positive association between retinopathy and age is limited to the group with diabetes of less than Io years' duration. We also found sex differences in retinopathy prevalence which were not large enough to rule out attributing them to chance.

\section{References}

BURDITT, A. F., CAIRD, F. I., and DRAPER, G. J. (I968) Quart. F. Med., n.s. 37, 303

CORNFIEld, J., GORDON, T., and SMITH, w. w. (1961) Bull. int. Stat. Inst., 38, Part III, 97

GOLDBERG, M. F. (1972) Israeli F. med. Sci., 8, I 3 I I

JaCKson, w. P. U., Goldin, c., and marine, n. (I966) S. Afr. med. F., 40, 206

Kahn, H. A.. herman, J. B., Medalie, J. H., Neufeld, H. N., Riss, E., and goldbourt, U. (I97I) J. chron Dis.,

23, 6 I 7 